\title{
A brief history of fish genetics in Brazil
}

\author{
Fausto Foresti \\ Departamento de Morfologia, Instituto de Biociências, Universidade Estadual Paulista, Botucatu, \\ SP, Brazil. \\ Key words: fish genetics, history, Brazil.
}

Received: December 4, 2007; Accepted: March 24, 2008.

\section{Introduction - The Early Years}

To talk about history usually involves references and citating persons, institutions and their relationships along the time, and it is certainly impossible to avoid a personal view of the facts. The beginnings of fish genetics in Brazil in a permanent and organized way involves research developed early in the sixties by Sílvio de Almeida Toledo Filho at the Biosciences Institute of the University of São Paulo, a researcher who, in my opinion and in that of many others, is perhaps the most important person in the field of fish genetics in Brazil ever since the early years of this discipline. Although having received his graduate training in Drosophila genetic, Silvio's research on fish genetics began in the late 1960s, when Ove Frydenberg from Denmark, recognized for his work on protein electrophoresis and its application to population genetics of Atlantic cod visited our country. The introduction of protocols for this technique in the routine of local laboratories, considered at that time as an important technological achievement, was perhaps the major initial step in the advancement of fish genetic research in Brazil.

Protein electrophoresis generated much interest among Brazilian researchers and was a quickly adopted technique that resulted in the establishment of new research options for laboratories devoted to the study of fish populations. Thus, important research groups in fish genetics were established in Rio Grande do Sul by Professor José Levy, in Amazonia by Professor Aylton Teixeira, and in Paraná by Professor Ernesto Renesto, to name just a few of the most prominent ones at that time. Many of these researchers and members of their groups have continued to use the protein electrophoresis techniques, even up to this day, for the resolution of fish genetic problems.

\section{Consolidation of Fish Genetics Research in Brazil}

In subsequent years, a major challenge was to establish fish genetics as a permanent and vigorous field of re-

Send correspondence to Fausto Foresti. Departamento de Morfologia, Instituto de Biociências, Universidade Estadual Paulista, 18618-000 Botucatu, SP, Brazil. E-mail: fforesti@ ibb.unesp.br. search in Brazil. One of the first difficulties was the development of infrastructure for fish breeding and selection experiments, and the second, the lack of sufficient researchers with experience in fish genetics. This led Sílvio and I to move the focus of our studies towards the identification of fish species and investigations of their population structure and dynamics using chromosomal and genetic/ biochemical markers with the hope of characterizing the extent of genetic diversity in various groups of Neotropical fish species. The use of isozymes as genetic markers, as outlined above, was a major advance to basic research in this field by that time, allowing to gain insight into the genetic structure of some fish species among the extensive and diverse fauna of Brazil.

More recently, starting in the 1990s, researchers started to apply new technologies of recombinant DNA and polymorphic DNA markers to questions of fish taxonomy, phylogeny, population structure and other evolutionary issues. Wild and cultured stocks of fish began to be studied with the use of this new technology, filling previous large gaps and resulting in new approaches concerning conservation and aquaculture programs. An interchange with researchers from many countries, prominent among them researchers from Hungary, Germany, the United States and Canada, has contributed much to the development of this field, further advancing and complementing initial studies by Brazilian researchers applying chromosome manipulation techniques to fish culture enhancement. Noteworthy here is the work developed in the Fish Reproduction Laboratory at Jaboticabal (SP), headed at that time by Dr. Newton Castagnolli. His large experience in fish reproduction and breeding, in association with the genetic support provided by our group, certainly contributed to the growing interest. Many important researchers visited our laboratories during that period, contributing with their experience to the development of the field.

As a result of these technical advances, the interest in the area of fish genetics grew significantly and today research groups and their laboratories multiply in the different regions of Brazil: for example, in Belo Horizonte, Botucatu, Bragança (Pará), Campo Grande, Campos do 
Jordão, Manaus, Maringá, Mogi das Cruzes, Pelotas, Porto Alegre, Recife, Rio de Janeiro, São Carlos, São Paulo, among others. Despite these revolutionary advances in the technology used for genetic studies, classic approaches to basic and applied fish genetics still maintains its ground in Brazil as can be seen when one has the opportunity of discussing genetic improvement of cultured fish stocks and population genetics of wild species with Ruy Alberto Caetano Correa Filho from Campo Grande.

\section{Fish Cytogenetics - The Office Poster as a Research Guide}

To continue the story, Sílvio worked on the one hand with the implementation of fish genetics using enzymatic and protein markers, while I initiated a systematic approach to fish cytogenetics based on currently available techniques. Although, a few published abstracts on fish chromosome research appeared sporadically in 1969 (Maruro Andrea's work with Synbranchus), in 1972 (Sônia M. Jim and Valter Toledo's work with Astyanax), as well as the work of J.L. Michelle and Catarina Satie Takahashi (with Loricariidae) and of Valter Toledo and Iris Ferrari (with Pimelodus), published in 1976 and 1977, respectively. It can be said that these publications were at that time only indicative marks to be followed by a growing community of Brazilian fish geneticists. More consistent and systematic studies began to appear at conferences, starting 1972 with the establishment of our group in Botucatu (SP). At that time, I conducted a broad review of fish chromosome structure and cytogenetics, summarized in a poster that was fixed on the wall of my office in order to better visualize the research activities developed in the different fish groups concerning their cytogenetics and the possibilities of potential research avenues. This poster remained on my office wall for a long time, being constantly revised, enlarged and consulted. Luis Antonio Carlos Bertollo may remember his visit to our laboratory around 1975 when talking about possibilities on fish cytogenetic research and telling how he came across the family Erythrinidae. Lurdes Foresti de Almeida Toledo discovered electric fish, Gymnotiformes, as potential research subjects after viewing this same poster. Even one of Lurdes' students, Claudio de Oliveira, years later began his doctoral work on Corydoras based on information shown in the poster.

\section{Technical Advances in Fish Cytogenetics}

The advance of fish cytogenetic research was greatly enhanced by technicial innovations in the preparation of metaphase chromosomes. The small size of fish chromosomes and their high number compared to mammalian chromosomes, and the then current "squash" or "crush" method of preparing chromosomes with direct fixation of tissue blocks in 50\% acetic acid, often resulted in few high quality metaphase spreads for analysis. This "squash" method with acetic acid fixation generally also resulted in injury to the fingers of the experimenter Luckily creativity blossomed. A few of the readers probably still remember, or have heard about the "crushing machine" invented by Orlando Moreira Filho for the preparation of chromosome spreads. The publication by McPhail and Jones (1975) on chromosome preparation spreads for cytogenetic studies by using cells in suspension was a methodological breakthrough. After modifications, such as colchicine treatment, and optimization in hypotonization time for tropical marine and freshwater fish species, this method became common practice and is still used today. The more recent application of procedures for mitotic stimulation adapted for fish resulted in a significant increase in the number of available mitotic cells for the preparation of metaphase chromosome spreads. This paved the way for the consolidation of the protocol currently used with great success in most laboratories.

\section{Fish Genetics as an Academic Discipline}

In hindsight, I consider 1975 as an important landmark in the establishment of fish genetic research as an academic discipline. It was an invitation from José Galizia Tundisi, who at that time was organizing the graduate programme in Ecology and Natural Resources at the São Carlos Federal University (UFSCar), that allowed Sílvio and I to develop a course on "Fish Genetics" and to my knowledge a course taught for the first time in Brazil. As a consequence, our participation in this programme permitted the supervision of graduate students in their research projects on fish genetics. The first student I supervised in fish cytogenetics was Pedro Manoel Galetti Junior (1979), initially for his Master's dissertation and later for his $\mathrm{PhD}$ thesis, defended in 1984. Many others followed, creating and consolidating a new group of researchers, the fish cytogeneticists, which received since 1978 the important collaboration of Luis Antonio Carlos Bertollo and Lurdes Foresti de Almeida Toledo. Luis and Lurdes, both with their PhD theses defended by this time, began to supervise graduate students including Orlando Moreira Filho and Claudio Oliveira, who well represent this burgeoning group of students of fish genetics in Brazil.

The growth of the Brazilian fish geneticists community not only multiplied the challenges for integration of the field, but also increased the experimental opportunities and approaches to solve problems in Neotropical fish genetics. In the 1980s, with three main centers for fish cytogenetics work, one located in Botucatu at São Paulo State University (UNESP), one in São Carlos at the São Carlos Federal University (UFSCar), and one in São Paulo at the Biosciences Institute of the University of Sao Paulo (IB/USP), interest grew in Neotropical fish cytogenetics and went through a period of rapid expansion. Masters and doctoral students began to study the main fish groups in an intensive and systematic manner, now providing a solid foundation for cyto- 
genetics of Neotropical fish species. The competence of this group is recognized owing to numerous publications in Brazilian and international scientific journals.

\section{Cytogenetics Revealing Diversity in Neotropical Fish}

I need to emphasize that the first phase of work on fish chromosomes in Brazil dealt mainly with gross comparisons between species. Owing to the techniques available at that time, most publications described karyotypes and merely confirmed the diploid number of chromosomes in a given fish species, but might also include Giemsa staining of chromosomes, identification of heterochromatin (Cbands), the localization of nucleolar organizing regions and descriptions of a few meiotic metaphases. A positive aspect of this initial period was the observation of the great diversity in karyotypes of Neotropical fish species, with numerical and structural polymorphism, supernumerary chromosomes, sex chromosome heteromorphisms, etc. The remarkable diversity revealed in fish by application of cytogenetic techniques attracted the attention of taxonomists. Moreover, differences in diploid number and formulae seen in fish karyotypes raised intriguing questions: Do individuals of similar morphology but with different chromosomal numbers captured in distant hydrographic basins belong to the same species? Could each cytotype represent a different species?

The idea of gathering fish cytogenetics and taxonomists to discuss phylogeny and taxonomy in the light of morphological, morphometric and karyotypic variation resulted in the organization of the "1st Evolutionary and Applied Cytogenetics of Neotropical Fish Symposium", which took place in São Carlos in 1986. Although the number of participants was small, they were nonetheless enthusiastic and determined, and eager to foster collaborations.

\section{The Neotropical Fish Cytogenetic and Genetics Symposia}

In the last decade, the methodology used in fish cytogenetic studies passed through many modifications, especially in Brazil, broadening and diversifying the field of study. The gradual technological advances, discussed at each of the meetings on Neotropical Fish Cytogenetic and Genetics organized every two years began to appear in the theses of our students, and was further stimulated by collaborative work with foreign researchers. As a consequence, the field of fish cytogenetics in Brazil, which had previously been only descriptive and confirmatory of karyotypic data, now began to investigate the structure and composition of chromosomes in detail. This was achieved by the use of base-specific fluorochromes, base analogues and restriction enzymes, which permitted the identification and localization of specific chromosomal segments and genes. More recently the application of fluorescent in situ hybridization
(FISH) of cloned DNA probes to interphase and metaphase chromosome spreads was another major step that spurred Brazilian fish cytogenetics research beyond the descriptive phase of karyotypes. The fusion of structural and molecular cytogenetics offers great potential for understanding the structure and composition of fish genetic material, and since these investigations are still in their infancy, there is much to be explored.

During the twenty years since the first Symposium, the area of fish cytogenetics has grown, multiplied and appeared in new environments. Today, dozens of laboratories located in different regions of the country are studying representatives of over 8,000 species of Neotropical fish using a variety of experimental approaches. As graduate students and postdoctoral fellows completed their training at one of the core institutes, they have moved on to join other laboratories focused on fish genetics, thereby forming a productive network of researchers. It is not possible to describe the work of these many laboratories, but it is possible to list a few of them: Barra do Garça, Bauru, Belém, Botucatu, Cascavel, Coxim, Cuibá, Curitiba, Lavras, Londrina, Macaé, Manaus, Marília, Maringá, Natal, Ponta Grossa, Recife, Rio Branco, Rio Claro, Rio de Janeiro, São Carlos, São Paulo, Viçosa, Uberlândia, among others. And every day we hear about new ones!

In retrospective, it can be unequivocally be stated that over these many years our dedicated efforts to the cause of fish genetics and cytogenetics has been a success. And it is with pride that we can see the large number of participants at each new symposium organized. Owing to its scientific importance, the commitment of faculty, students, and research groups involved, the symposium now became international being organized concomitantly with the " $\mathrm{I}$ st International Congress of Fish Genetics" which attracted many researchers from different countries from around the world.

\section{An Outlook}

What are the future challenges in fish genetics and cytogenetics for Brazilian researchers? What new technologies are likely to be developed? Which areas of fish genetics and cytogenetics will be most rewarding to pursue? In the search for new areas and methods it is worth mentioning a few that might become the most promising. These include a better exploitation of the great diversity of fish species existing in the Neotropical region, the characterization of new species of interest for fish culture, the production of polyploid and gynogenetic fish, the induction of monosex individuals by hormone treatment, and the development of transgenic fish. While these new technologies offer novel and intriguing possibilities for further research and development of aquaculture stocks, their widespread application in fish genetics programs still faces diverse impediments, including some of legal, philosophical, religious and ethical nature. 
With the development of techniques for high quality chromosome preparations and the recent application of fluorescent in situ hybridizations, the main focus in fish cytogenetics turns to defining chromosome structure and genomic mapping in Neotropical fish. With the integration of molecular genetics and structural cytogenetics, many productive avenues of fish cytogenetic research are waiting to be fully explored that include: understanding of chromosome structure and evolution, chromosome polymorphisms linked or not to sex determination, the structure and genetic functioning of sex chromosomes and supernumerary chromosomes, the latter feature commonly observed in Neotropical fish karyotypes.

With the application of modern molecular genetics techniques, advances in our knowledge and conservation of the biodiversity of Neotropical fish by the collaboration between cytogeneticists and taxonomists can be also anticipated. Multiple and multivariate analysis of molecular genetic marker studies and morphological data will allow for new interpretations of phylogenetic processes. This may well lead to a better or more complete understanding of the processes of speciation in Neotropical fishes.

It is also important, at this time, to reflect on the contributions made by Brazilian icthyocytogeneticists over the years, not only in terms of scientific and technological advances, but also for the enhancement of the quality of life. When one considers the vast faunal diversity and genetic variability in fish, basic genetic research has broadened in a decisive way our knowledge of fish species and populations. This knowledge will lead in the short to medium term to the characterization of essential genetic banks and the establishment of necessary management and conservation programs for this fauna.

In the field of aquaculture, the application of new technologies along with appropriate management strategies has the potential to significantly increase food production. Already we are seing a quantitative increase in the production of cultured fish using traditional selection methods for reducing culture time (e.g. pacu), and the production of hybrids, sterile and monosex strains (e.g., tilápias). The appli- cation of classic breeding, selection and hybridization methods for bloodstock improvement still plays a central role in the growing aquaculture industry in Brazil, but novel genetic tools will soon complement these approaches. For example, chromosome and molecular markers have been developed and used for the identification of wild and cultured fish stocks, and it is now possible to ensure the maintenance of genetic variability in cultured stocks using these genetic tools. Finally, with the manipulation of fish chromosomes and perhaps transgenics, research conducted in laboratories and expanded to fish farms, will become an ever more important tool in the production and use of this of animal protein source as food.

We can conclude the message which sets the contributions to this special volume on Fish Genetics into a historical context by recognizing the important contributions that many of its authors have made to the development of fish cytogenetics and genetics in Brazil. Over the years, we have seen the research community growing and diversifying its research activities, but always remaining united in the pursuit of science. The success of this endeavour in the field of fish genetic and cytogenetics can be easily measured by the growing number of students and laboratories in Brazil and by the foreign researchers attending the scientific organized by the group of Brazilian fish geneticists. In an appropriation of the view of Professor Noel Wilkins, offered during a recent congress, this growing group in fact also forms a virtual and committed society with no annual fees that meets from time to time to discuss science; but more than that, to celebrate friendship!

\section{Acknowledgment}

I would like to thank Jonathan M. Wright and Klaus Hartfelder who reviewed and greatly improved the version in English. This manuscript is based on a presentation given by the author during the It International Congress of Fish Genetics and $\mathrm{XI}^{\text {th }}$ Brazilian Symposium on Fish Cytogenetics and Genetics, held in 2006 in São Carlos, SP, Brazil.

Assistant Editor: Klaus Hartfelder 